\title{
An English-language adaptation and validation of the Political Efficacy Short Scale (PESS)
}

\author{
Katharina Groskurth ${ }^{*}$, Désirée Nießen, Beatrice Rammstedt and Clemens M. Lechner
}

\begin{abstract}
The Political Efficacy Short Scale (PESS) is the English-language adaptation of the German-language Political Efficacy Kurzskala (PEKS); it measures perceived political efficacy with four items. PESS comprises two subscales-internal and external political efficacy - with two items each. Internal political efficacy refers to the belief in one's own political effectiveness; external political efficacy refers to the belief in the responsiveness of the political system to citizens' concerns. Completion time for all four items is less than 30 s. The items of the German-language source version were translated into English using the TRAPD approach. The present study empirically validated the English-language adaptation (PESS) based on a heterogeneous quota sample in the UK. The results show that the reliability and validity coefficients of the English-language adaptation are sufficiently high and that they are comparable to those of the German-language source version. In addition, the scale showed strict measurement invariance (i.e., equal loadings, intercepts, and uniquenesses) when comparing the UK and Germany, which indicates the comparability of manifest scale scores (means and variances) and correlations across the two nations. As a short scale, PESS lends itself particularly to the measurement of political efficacy in survey contexts in which assessment time or questionnaire space is limited. It is applicable in a variety of research disciplines, including political science, sociology, psychology, and economics.
\end{abstract}

Keywords: Political Efficacy Short Scale, Personal political effectiveness, Responsiveness of the political system, Englishlanguage adaptation, Validation study in the UK

\section{Introduction}

"Sense of political efficacy" consists of two dimensions: internal and external political efficacy (Balch, 1974). Internal political efficacy refers to the belief in one's own political effectiveness; external political efficacy refers to the belief in the responsiveness of the political system to citizens' concerns (Craig \& Maggiotto, 1982). It is a highly important political construct because the subdimensions predict, for instance, political participation or political trust. As scales to measure political efficacy were often lengthy and subject to psychometric limitations (e.g., Craig \&

\footnotetext{
* Correspondence: katharina.groskurth@gesis.org

GESIS - Leibniz Institute for the Social Sciences, P.O. Box 122155,68072 Mannheim, Germany
}

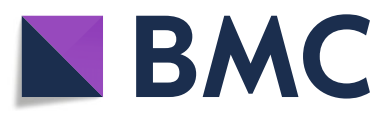

(C) The Author(s). 2020 Open Access This article is licensed under a Creative Commons Attribution 4.0 International License, which permits use, sharing, adaptation, distribution and reproduction in any medium or format, as long as you give

appropriate credit to the original author(s) and the source, provide a link to the Creative Commons licence, and indicate if changes were made. The images or other third party material in this article are included in the article's Creative Commons licence, unless indicated otherwise in a credit line to the material. If material is not included in the article's Creative Commons licence and your intended use is not permitted by statutory regulation or exceeds the permitted use, you will need to obtain permission directly from the copyright holder. To view a copy of this licence, visit http://creativecommons.org/licenses/by/4.0/. 


\section{Theoretical background}

\section{What is political efficacy?}

The concept "sense of political efficacy" was developed by

Campbell et al. (1954, p. 187), who defined it as:

The feeling that individual political action does have, or can have, an impact upon the political process, i.e., that it is worthwhile to perform one's civic duties. It is the feeling that the individual citizen can play a part in bringing about this change.

The focus of Campbell and colleagues' research was on perceived political efficacy as a potential explanatory variable for variation in electoral participation. Later work on the construct diverged into two different perspectives: One line of research focused on the importance of political efficacy for the individual (e.g., Renshon, 1975); the other focused on the importance of political efficacy for the political system (e.g., Almond \& Verba, 1963).

\section{Internal and external political efficacy}

Campbell et al. (1954) conceived "sense of political efficacy" as a unidimensional construct. Balch (1974) was the first to empirically examine the factor structure of a slightly modified version of Campbell et al.'s original measure of the concept. He extracted two components of "sense of political efficacy": internal political efficacy (personal effectiveness; Craig \& Maggiotto, 1982) and external political efficacy (system responsiveness; Craig \& Maggiotto, 1982). More specifically, internal political efficacy refers to the belief that one is capable of understanding politics and engaging in political acts. In contrast, external political efficacy refers to the individual's belief in the responsiveness of political institutions and leaders to citizens' concerns (W. E. Miller \& Traugott, 1989).

The relationship between internal and external efficacy is typically weak because these two components of political efficacy have different referents: oneself (in the case of internal political efficacy) and politicians and political institutions (in the case of external political efficacy; Craig \& Maggiotto, 1982; W. E. Miller \& Traugott, 1989). Previous findings have shown that internal and external political efficacy are positively associated with each other in democratic contexts (e.g., Craig, 1979; Morrell, 2003; Muller, 1970; Niemi et al., 1991) but largely independent of each other in authoritarian regimes (e.g., Muller, 1970). For instance, Muller (1970) found a medium correlation between internal and external political efficacy in the United States but an almost zero correlation in Mexico. This suggests that, through socialization, people in democratic regimes learn to believe in the responsiveness of their governments (see also
Easton \& Dennis, 1967). The existence of a norm of regime responsiveness encourages people to develop the skills and, accordingly, the self-conviction to be able to exert influence on governmental decisions (Muller, 1970). In contrast, people in authoritarian regimes may experience a discontinuity in regime responsiveness during their socialization process, which hinders them from acquiring a stable political norm of regime responsiveness. Although people in authoritarian regimes may possess the skills and, accordingly, the conviction to influence politics, the skills and conviction do not match reality. Due to the authoritarian nature of the regime, people are unable to make use of their political skills. They cannot exert political influence; the government does not respond to their concerns (Muller, 1970). Thus, the strength of the association between internal and external political efficacy varies with regime type.

Internal and external political efficacy also show different patterns of associations with external correlates (e.g., potential causes or effects). On the one hand, internal political efficacy is robustly associated with participation in campaign- and community-oriented activities (e.g., Craig, 1979; Morrell, 2003; Niemi et al., 1991). High internal political efficacy corresponds also with (positive attitudes toward) political protest (e.g., Balch, 1974; Craig \& Maggiotto, 1982; Šerek et al., 2017). Thus, participatory experiences seem to boost individuals' perceived political effectiveness (Šerek et al., 2017). Furthermore, high educational attainment, social status, personal interest, political attentiveness, and political information lead to stronger convictions of internal political efficacy (e.g., Craig \& Maggiotto, 1982; Morrell, 2003; Niemi et al., 1991). Internal political efficacy is also related to personality: People who are high in Openness are commonly critical thinkers; people who are high in Extraversion are often dominant, assertive, and persuasive. Thus, these two Big Five traits are commonly associated with (internal) political efficacy (Vecchione \& Caprara, 2009).

Convictions about external political efficacy have been found to vary as a function of political context and regime performance (Coleman \& Davis, 1976). For example, a nation with a functioning democratic system elicits a strong perception of external political efficacy (Coleman \& Davis, 1976). External political efficacy is also closely connected to political trust (e.g., Balch, 1974; Craig, 1979; Niemi et al., 1991). A. H. Miller (1974) defined political distrust as the belief in a dysfunction of the political system in which political outputs diverge from the public's interest. Thus, it is reasonable that people put trust in their government as long as they are convinced that it responds to the public's concerns-that is, as long as people have a strong conviction of external political efficacy (Craig \& Maggiotto, 1982). In contrast, 
high willingness to engage in political protest is associated with low external political efficacy (Balch, 1974; Šerek et al., 2017), which may be due to "disappointing outcomes, in which the demands of the protesting citizens were not fulfilled" (Šerek et al., 2017, p. 354).

\section{Development of the Political Efficacy Short Scale (PESS)}

In 1952, the American National Election Studies (ANES) first included a measure of sense of political efficacy, which was conceived of as a unidimensional construct (e.g., Campbell et al., 1954; Morrell, 2003). After theoretical and empirical findings underlined the twodimensionality of the construct (Balch, 1974), researchers tried to map Campbell and colleagues' (1954) original four items onto the two dimensions, internal and external political efficacy. As these attempts encountered problems with reliability and validity, researchers constructed new scales or employed variants of the original items. However, the new scales and the variants of the original items were still ambiguously defined, and it was not possible to clearly differentiate between the constructs of internal and external political efficacy (for an overview and empirical analyses, see Craig \& Maggiotto, 1981; Morrell, 2003; Vetter, 1997). To remedy the issues encountered in covering the two dimensions with Campbell et al.'s original item set, several short scales were newly developed. Some of these newly developed short scales covered only one dimension, most often internal political efficacy (e.g., the four-item Perceived Political Self-Efficacy Scale-Short Form by Vecchione et al., 2014). Others incorporated items in equal share for both internal and external political efficacy. Besides the political efficacy scale of the European Social Survey (ESS, n.d.), Beierlein, Kemper, et al. (2014b) constructed a four-item short scale of internal and external political efficacy with five response optionsthe Political Efficacy Kurzskala (PEKS). Whereas the former has already been translated into many different European languages (e.g., German, English, Dutch, Spanish), the latter has, to date, only been validated for the German language, even though it was also available in English. We, however, deem PEKS as more promising than the political efficacy scale of the ESS because the items of PEKS are worded more succinctly. Because Beierlein, Kemper, et al. (2014b) used statements instead of questions, the items of PEKS are shorter and therefore more economical than in the ESS. Furthermore, the labels in the response options differ in the ESS, whereas they stayed the same across items of PEKS, which makes PEKS more comparable.

In the following, we will focus on the short scale developed by Beierlein, Kemper, et al. (2014b) - PEKS — which measures internal and external political efficacy validly and with sufficient reliability despite its short length. The authors also reported evidence for the validity of the scale. The German-language scale was developed based on theoretical and empirical analyses. A multistep procedure was followed: First, by reanalyzing survey data (Andreß et al., 2011; Falter et al., 2015), Beierlein, Kemper, et al. (b) compared different operationalizations of political efficacy, including items from Niemi et al. (1991) and Vetter (1997). Based on this sample of items, they selected those items that best represented the theoretical bandwidth of (self-)convictions of political competencies and influence. Second, experts in survey research linguistically modified the selected items, especially to reduce the cognitive effort needed to understand them (Beierlein, Kemper, et al., 2014b). In doing so, test fairness was ensured-that is, the items were constructed to be unbiased across different social strata. In order to arrive at an ultra-short scale, only two items per dimension were finally selected based on the analysis of the first sample. Third, based on two different samples, including one random sample representative of the adult population in Germany, Beierlein, Kemper, et al. (2014b) validated the German-language PEKS, administered as a personal interview. The results supported good psychometric properties of the scale (see Beierlein, Kemper, et al., 2014b).

To enable their scale to be used outside the German research context, Beierlein, Kemper, et al. (2014b) translated the German-language version into English. Following the International Test Commission (2010) recommendations, the translation process followed the TRAPD approach (Translation, Review, Adjudication, Pretesting, and Documentation; Harkness, 2003) and consisted of two major steps: First, two professional translators (native speakers) translated the items independently of each other; one of them translated into British English, the other into American English. Second, the translation proposals were discussed, revised, and finalized by a team comprising the two translators, researchers with expertise in the area of political efficacy, and a researcher proficient in questionnaire translation.

The aim of the present study is to validate the Englishlanguage adaptation of PEKS, the Political Efficacy Short Scale (PESS), and to compare its psychometric properties with those of the German-language source version. Additionally, as the hypothesized two-factor structure of PESS has not yet been confirmed for the German-language version, the present study addresses this research gap and evaluates the factor structure for both the German and English versions. If both versions prove to be psychometrically valid and of high quality, the measure will advance cross-cultural research on political efficacy.

\section{Method}

\section{Samples}

To investigate the dimensionality and psychometric properties of PESS, the English-language adaptation of 
PEKS, and their comparability with those of the German-language source instrument, we assessed both versions in a web-based survey (using computer-assisted self-administered interviewing [CASI]). The survey was conducted in parallel in the United Kingdom (UK) and Germany (DE) by the online access panel provider respondi AG.

Fielding took place in January 2018. For both the UK and Germany, quota samples were drawn that represented the heterogeneity of the adult population in terms of age, gender, and educational attainment based on the latest German census from 2011 (https://ergebnisse.zensus2011.de). Only native speakers of the respective languages were recruited. Respondents were financially rewarded for their participation. To allow for the investigation of test-retest stability of the scale in both nations, a subsample was reassessed after approximately 3 to 4 weeks $\left(M d n_{\mathrm{UK}}=28\right.$ days; $M d n_{\mathrm{DE}}=20$ days).

Only respondents who completed the full questionnaire-that is, who did not abort the survey prematurely-were included in our analyses. This yielded gross sample sizes of $N_{\mathrm{UK}}=508$ for the UK and $N_{\mathrm{DE}}=513$ for Germany. These samples were further reduced by excluding invalid cases based on three criteria. First, respondents with an ipsatized variance-that is the withinperson variance across items (Kemper \& Menold, 2014) - below 5\% were excluded. The second criterion was the Mahalanobis distance of a person's response vector from the average sample response vector (Meade \& Craig, 2012). If respondents fell within the upper $2.5 \%$ of the sample distribution of the Mahalanobis distance, they were excluded from the sample. Third, response times were evaluated. If respondents answered all items in-on average-less than $1 \mathrm{~s}$ per item, they were excluded. ${ }^{1}$ The outlined approach resulted in the exclusion of $8 \%$ of cases in both the UK and the German subsamples, yielding net sample sizes of $N_{\mathrm{UK}}=468$ (retest: $N_{\mathrm{UK}}$ $=111)$ and $N_{\mathrm{DE}}=474$ (retest: $N_{\mathrm{DE}}=117$ ). Table 1 depicts in detail the sample characteristics and their distribution. Table S1 in the Additional File 1 of the Supplementary Online Material shows the target and real sample size per quota.

\section{Material}

The online surveys were conducted in English for the UK sample and in German for the German sample using PESS and PEKS, respectively. PESS/PEKS consists of

\footnotetext{
${ }^{1}$ Our intention in choosing relatively liberal cutoff values was to avoid accidentally excluding valid cases and thereby creating a systematic bias in our data.
}

Table 1 Sample characteristics, UK and Germany

\begin{tabular}{lll}
\hline & UK & Germany \\
\hline$N$ & 468 & 474 \\
Mean age in years (SD) [range] & $45.2(14.5)$ [18-69] & 44.0 (14.4) [18-69] \\
Proportion of women (\%) & 52.6 & 50.0 \\
Educational attainment (\%) & & \\
$\quad$ Low & 34.8 & 33.5 \\
Intermediate & 32.1 & 33.8 \\
High & 33.1 & 32.7
\end{tabular}

The educational attainment levels were as follows: low = never went to school/Skills for Life/1-4 GCSEs A*-C or equivalent (Germany: ohne Bildungsabschluss/Hauptschule [no educational qualifications; lower secondary leaving certificate]); intermediate $=5$ or more GCSEs $A^{*}-C /$ vocational GCSE/ GNVQ intermediate or equivalent (Germany: mittlerer Schulabschluss [intermediate school leaving certificate]); high $=2$ or more A-levels or equivalent (Germany: (Fach-)Hochschulreife [higher education entrance qualification])

four items measuring (internal and external) political efficacy. The PESS items are displayed in Table 2 and in the Additional File 2 in the Supplementary Online Material (for the original German-language items, see the Additional File 3 in the Supplementary Online Material and Beierlein, Kemper, et al., 2014b). Items 1 and 3 belong to the internal political efficacy subscale, and items 2 and 4 belong to the external political efficacy subscale. All items are positively worded in relation to the underlying construct. Items are answered using a 5-point rating scale ranging from "do not agree at all" (1), through "hardly agree" (2), "somewhat agree" (3), and "mostly agree" (4), to "completely agree" (5).

We validated PESS against different constructs. Our choice of correlates was driven by theoretical considerations and by data availability because PESS was part of a multi-theme survey. On theoretical grounds, we selected the following correlates: (1) correlates that reflect general psychological resources (i.e., [a] the Big Five dimensions of personality, [b] general self-efficacy, [c]

Table 2 Items of PESS

\begin{tabular}{llc}
\hline No. $\quad$ Item & Subscale \\
\hline 1 & $\begin{array}{l}\text { I am good at understanding and assessing } \\
\text { important political issues. }\end{array}$ & Internal \\
2 & $\begin{array}{l}\text { Politicians strive to keep in close touch } \\
\text { with the people. }\end{array}$ & External \\
3 & $\begin{array}{l}\text { I have the confidence to take active part } \\
\text { in a discussion about political issues. }\end{array}$ & Internal \\
4 & $\quad$ Politicians care about what ordinary people think. & External \\
\hline $\begin{array}{l}\text { The instructions are as follows: "In the following we are interested in your opinion } \\
\text { concerning politics. You can agree to the statements below to a greater or lesser } \\
\text { extent. Please indicate to what extent you agree or disagree with each } \\
\text { of the statements." } \\
\text { Internal = internal political efficacy, External= external political efficacy }\end{array}$
\end{tabular}


locus of control, [d] optimism-pessimism, [e] interpersonal trust, and [f] general life satisfaction), which we expected to correlate positively with internal political efficacy as a domain-specific manifestation of personal resources; (2) correlates that reflect political and social attitudes, values, and behaviors (e.g., [g] political preferences, [h] authoritarianism, and [i] justice sensitivity), which we expected to correlate with internal and external political efficacy in different and non-negligible ways; (3) sociodemographic correlates, whose correlations with PESS would indicate differences in internal and external political efficacy across subpopulations such as age groups, gender, and educational attainment, which one would generally assume to exist. We also (4) probed the proneness of PESS for socially desirable responding by correlating it with (j) a social desirability scale. ${ }^{2}$ Accordingly, the following short-scale measures were also administered as part of the survey:

a) The extra-short form of the Big Five Inventory-2 (BFI-2-XS; English version: Soto \& John, 2017; German version: Rammstedt et al., 2020)

b) The General Self-Efficacy Short Scale-3 (GSE-3; (Doll, E. S., Nießen, C., Schmidt, I., Rammstedt, B., \& Lechner, C. M.: The General Self-Efficacy Short Scale-3 (GSE-3): An English-language adaptation, in preparation))/Allgemeine Selbstwirksamkeit Kurzskala (ASKU; Beierlein, Kovaleva, et al., 2014)

c) The Internal-External Locus of Control Short Scale-4. (IE-4; (Nießen, D., Schmidt, I., Groskurth, K., Rammstedt, B., \& Lechner, C. M.: An Englishlanguage adaptation of the Internal-External Locus of Control Short Scale-4 (IE-4), in preparation))/ Internale-Externale-Kontrollüberzeugung-4 (Kovaleva et al., 2014)

d) The Optimism-Pessimism Short Scale-2 (SOP2; (Nießen, D., Groskurth K., Kemper, C. J., Rammstedt, B., \& Lechner, C. M.: An Englishlanguage adaptation of the Optimism-Pessimism Short Scale-2 (SOP2), in preparation))/Skala Optimismus-Pessimismus-2 (Kemper, Beierlein, Kovaleva, et al., 2014)

e) The Interpersonal Trust Short Scale (KUSIV3; Nießen, Beierlein, et al., 2020)/Kurzskala

\footnotetext{
${ }^{2}$ The German-language source version of PESS has multiple indications of construct validity with political constructs such as political interest or political engagement (see Beierlein, Kemper, et al., 2014b). We did not validate PESS against other existing political efficacy scales or related constructs (e.g., political protest) because the validation of the English-language PESS was administered as part of a comprehensive online survey for the validation of various short scales. Therefore, there was no room for further validation scales. However, future research needs to address this point and survey PESS in combination with related/standard political efficacy scales and further political constructs.
}

Interpersonelles Vertrauen (Beierlein, Kemper, et al., 2014a)

f) The General Life Satisfaction Short Scale (L-1; Nießen, Groskurth, Rammstedt, et al., 2020)/ Kurzskala zur Erfassung der Allgemeinen Lebenszufriedenheit (Beierlein et al., 2015)

g) The political Left-Right Self-Placement scale (English and German versions: Breyer, 2015)

h) The Authoritarianism Short Scale (KSA-3; Nießen, Schmidt, et al., 2019)/Kurzskala Autoritarismus (Beierlein, Asbrock, et al., 2014)

i) The Justice Sensitivity Short Scales-8 (JSS-8; (Groskurth, K., Nießen, D., Beierlein, C., Baumert, A., Rammstedt, B., \& Lechner, C. M.: An EnglishLanguage Adaptation and Validation of the JusticeSensitivity-Scales-8 (JSS-8), in preparation))/ Ungerechtigkeitssensibilität-Skalen-8 (USS-8; Beierlein, Baumert, et al., 2014)

j) The Social Desirability-Gamma Short Scale (KSEG; Nießen, Partsch, et al., 2019)/Kurzskala Soziale Erwünschtheit-Gamma (Kemper, Beierlein, Bensch, et al., 2014)

In addition, a set of sociodemographic variables (employment, income, educational attainment, age, and gender) was assessed. Employment was surveyed with the following nominal categories: "employed" (1), "self-employed" (2), "out of work and looking for work" (3), "out of work but not currently looking for work" (4), "doing housework" (5), "pupil/student" (6), "apprentice/internship" (7), "retired" (8), and "none of what is mentioned above" (9). We recoded the variable into the following categories: "unemployed" (1), which comprises "out of work and looking for work" and "out of work but not currently looking for work," and "employed" (2), which comprises "employed" and "self-employed." All other categories were recoded as missing values.

We ran all statistical analyses with $\mathrm{R}$ (version 3.6.1), using the packages lavaan (Rosseel, 2012), psych (Revelle, 2018), and semTools (Jorgensen, et al., 2019). The analysis code can be found in the Additional File 4, and the output can be found in the Additional File 5 in the Supplementary Online Material.

\section{Results}

In this study, we evaluated PESS, the English-language adaptation of PEKS, in the UK, and investigated its comparability with the German-language source version in Germany. We analyzed descriptive statistics and psychometric quality criteria-more precisely, objectivity, reliability, and validity - in both language versions. Moreover, we assessed test fairness across both nations with measurement invariance tests. 
Table 3 Descriptive statistics for the PESS/PEKS items by nation

\begin{tabular}{|c|c|c|c|c|c|c|c|c|}
\hline & \multicolumn{2}{|l|}{$M$} & \multicolumn{2}{|l|}{$S D$} & \multicolumn{2}{|c|}{ Skewness } & \multicolumn{2}{|c|}{ Kurtosis } \\
\hline & $\overline{\mathrm{UK}}$ & $\mathrm{DE}$ & $\overline{U K}$ & $\mathrm{DE}$ & $\overline{U K}$ & $\mathrm{DE}$ & UK & $\mathrm{DE}$ \\
\hline Item 1 & 3.05 & 3.42 & 1.10 & 0.99 & -0.29 & -0.46 & -0.58 & -0.06 \\
\hline Item & 2.12 & 2.00 & 1.05 & 0.97 & 0.84 & 0.91 & 0.14 & 0.49 \\
\hline Item 3 & 2.83 & 3.23 & 1.24 & 1.21 & 0.08 & -0.24 & -0.96 & -0.81 \\
\hline em 4 & 2.08 & 1.98 & 1.07 & 0.93 & 0.82 & 0.82 & -0.12 & 0.36 \\
\hline
\end{tabular}

UK United Kingdom $(N=468), D E$ Germany $(N=474)$

\section{Descriptive statistics and reference ranges}

We analyzed the descriptive statistics and reference ranges separately for both PESS and PEKS. Table 3 shows the mean, standard deviation, skewness, and kurtosis of each of the four items for PESS/PEKS separately for the UK and German samples. More detailed information on descriptive statistics (and reference ranges) of the PESS/PEKS scale scores can be found in the Additional File 6: Table S2 in the Supplementary Online Material (for the total population and separately for gender and age groups in both nations).

\section{Objectivity}

Researchers should be able to apply, evaluate, and interpret PESS/PEKS objectively. As PESS/PEKS contains fixed written instructions, a standardized order of the items, and a fixed number of labeled categories, it can be applied objectively. PESS/PEKS data can also be evaluated objectively because the scale is accompanied by strict rules on how to model it and how to build sum scores. PESS/PEKS can be interpreted objectively because reference values (i.e., descriptive statistics) have been provided.

\section{Reliability}

To estimate the reliability of the two PESS/PEKS subscales (internal and external political efficacy), we computed McDonald's omega (McDonald, 1999; Raykov, 1997) and test-retest stability. McDonald's omega was relatively high for both the UK and Germany (UK: $\omega_{\text {Internal }}=.88, \omega_{\text {External }}$ $\left.=.84 ; \mathrm{DE}: \omega_{\text {Internal }}=.86, \omega_{\text {External }}=.86\right)$. The test-retest stability $\left(\mathrm{UK}: r_{t t}-\right.$ Internal $=.83, r_{t t}-$ External $=.68$; DE: $r_{t t}$ - Internal $=.87, r_{t t}$ - External $\left.=.75\right)$ after approximately 3 to 4 weeks $\left(M d n_{\mathrm{UK}}=28\right.$ days; $M d n_{\mathrm{DE}}=20$ days) was generally lower than McDonald's omega in both nations, but it was still acceptable.

In sum, PESS/PEKS achieved internal consistencies and test-retest stabilities ranging from .68 to .88 in both nations. Especially in view of the fact that PESS/PEKS comprises only two items per subscale, these reliabilities are relatively high and are sufficient for research purposes (e.g., Aiken \& Groth-Marnat, 2006; Kemper et al., 2019).

\section{Validity}

To garner evidence for the validity of PESS/PEKS, we examined its factorial validity and nomological network.

\section{Factorial validity}

As noted earlier, political efficacy was initially theorized as a unidimensional construct, but later refined to comprise two separate dimensions, internal political efficacy and external political efficacy (e.g., Balch, 1974). In line with the development of the construct, we tested the dimensionality of PESS with both a unidimensional and a two-dimensional confirmatory factor analysis model. Both models are considered to fit the data well if heuristics for model fit indices are met. We followed the heuristics of $\mathrm{Hu}$ and Bentler (1999), whereby a Comparative Fit Index (CFI) of around .950 (or higher), a Root Mean Square Error of Approximation (RMSEA) of .060 (or lower), and a Standardized Root Mean Square Residual (SRMR) of around .080 (or lower) imply a good model fit. Lower values of information criteria such as the Bayesian information criterion (BIC) point to a better model fit. We analyzed separate models for the UK and German data. For identification purposes, we fixed the latent variance(s) to one and the latent mean(s) to zero. We used robust maximum likelihood estimation (MLR) to fit the model.

When a unidimensional model was fit to the data, fit indices pointed to a poor model fit (UK/Germany: $X^{2}(2)=$ $193.79 / 217.16, p<.001$, CFI $=.684 / .588$, RMSEA $=.453 /$ .476$, SRMR $=.139 / .183, \mathrm{BIC}=5208 / 5120){ }^{3}{ }^{3}$ The findings showed that the factor structure was misspecified by assuming that only one factor lies behind the four items.

We further tested the assumption that two correlated factors (i.e., internal and external political efficacy) lay behind the four items. We tested two different versions of a two-factor model: one with freely estimated (i.e., congeneric) and one with fixed factor loadings (i.e., essentially tauequivalent) across dimensions. Most fit indices of the congeneric model pointed to a good model fit in both nations (UK/Germany: $\chi^{2}(1)=11.35 / 24.76, p=.001 / p<.001$, CFI $=.983 / .955$, RMSEA $=.149 / .224$, SRMR $=.012 / .010$, $\mathrm{BIC}=4942 / 4782){ }^{4}$ The same also applied to the essentially tau-equivalent model (UK/Germany: $X^{2}(4)=28.58 / 14.20$, $p<.001 / p=.007$, CFI $=.959 / .980$, RMSEA $=.115 / .073$, SRMR $=.062 / .069, \mathrm{BIC}=4940 / 4773) .^{5}$ Because the fit of

\footnotetext{
${ }^{3}$ Taking the sample size into account prevents biased fit indices and yields the so-called robust CFI and robust RMSEA values in R/lavaan (Brosseau-Liard \& Savalei, 2014; Brosseau-Liard et al., 2012): UK-robust CFI $=.670$, robust RMSEA $=.547 ; \mathrm{DE}-$ robust $\mathrm{CFI}=.539$, robust RMSEA $=.604$.

${ }^{4} \mathrm{UK}$-robust CFI $=.989$, robust $\mathrm{RMSEA}=.142 ; \mathrm{DE}$-robust $\mathrm{CFI}=$ .994 , robust RMSEA $=.098$.

${ }^{5} \mathrm{UK}$-robust $\mathrm{CFI}=.973$, robust $\mathrm{RMSEA}=.112$; $\mathrm{DE}$-robust $\mathrm{CFI}=$ .987 , robust $\mathrm{RMSEA}=.073$.
} 


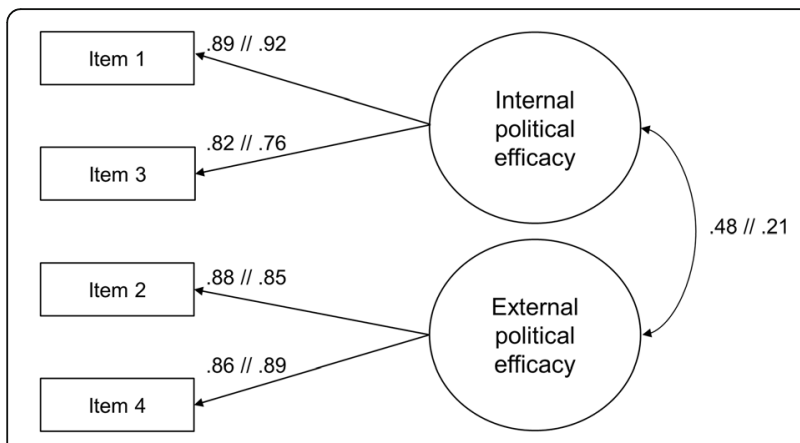

Fig. 1 Two-factor essentially tau-equivalent measurement model of PESS/PEKS with standardized coefficients. The coefficients of the German sample follow those of the UK sample after the double slash. Item error terms have been omitted for clarity. $N_{U K}=468 ; N_{D E}=474$

the more constrained (i.e., essentially tau-equivalent) model was comparable with or even better than that of the less constrained (i.e., congeneric) model according to several fit indices (UK: RMSEA, BIC; Germany: $\chi^{2}$, CFI, RMSEA, BIC), we accepted the essentially tau-equivalent model in both nations (Fig. 1). The empirical structure of PESS/PEKS confirmed the theoretical two-factor structure of political efficacy, thereby corroborating factorial validity.

In the essentially tau-equivalent model, internal and external political efficacy correlated at $r=.47$ (UK) and $r$ $=.21$ (DE). This correlation can also be captured by a latent variable (with equal factor loadings on the factors of internal and external political efficacy). This so-called second-order factor model is equivalent to the model with two correlated factors. With a second-order factor model, the covariance between internal and external political efficacy can be used for further analysis. The correlation between the two factors is, however, often very small because the factors have different referents (oneself vs. politicians and political institutions; Craig \& Maggiotto, 1982), and the correlation varies with regime type (Muller, 1970). Thus, we do not recommend using the total scale score across both factors. Unit-weighted mean scores should be computed separately for the subscales of political efficacy. ${ }^{6}$

\section{Nomological network}

After corroborating factorial validity, we investigated the nomological network of PESS/PEKS. As the nomological network was computed based on manifest correlations,

\footnotetext{
${ }^{6}$ We suggest that individual answers should be aggregated to the subscale level only if there are no missing values on any of the two items. If there are missing values on one or more items, researchers should use appropriate methods for handling missing data, such as multiple imputation or full information maximum likelihood estimation.
}

the reported values represent lower-bound estimates of the true associations. The correlation coefficients are depicted in Table 4; their interpretation is based on Cohen (1992), who differentiated between a small $(r \geq .10)$, medium $(r \geq .30)$, and strong effect $(r \geq .50)$. Due to alpha accumulation through multiple testing, only coefficients with a significance level of $p<.001$ are interpreted (Table 4 displays unadjusted $p$ values). In order to investigate the nomological network, we correlated PESS/ PEKS with the constructs outlined in the Material section above.

As outlined in the Theoretical background section, internal political efficacy should be associated with personality (especially Big Five Openness and Extraversion; e.g., Vecchione \& Caprara, 2009). In line with this expectation, we found that, in both nations, respondents who scored high in Openness and/or Extraversion (see also Beierlein, Kemper, et al., 2014b; Cooper et al., 2013; Vecchione \& Caprara, 2009), and respondents who scored high in Emotional Stability (see also Beierlein, Kemper, et al., 2014b), had higher degrees of internal political efficacy. Conscientiousness was negatively related to internal political efficacy in Germany. External political efficacy was uncorrelated to (almost) all Big Five dimensions (see also Beierlein, Kemper, et al., 2014b).

We also assumed that political efficacy would be positively associated with general self-efficacy because it is a specific manifestation of this trait (Condon \& Holleque, 2013). Our findings corroborated that expectation with respect to internal political efficacy (see also Beierlein, Kemper, et al., 2014b; Condon \& Holleque, 2013). However, external political efficacy was unrelated to general self-efficacy (see also Beierlein, Kemper, et al., 2014b).

High political efficacy suggests a "feeling of mastery over political processes" (Shrivastava, 1989, p. 171; see also Minton, 1972). Thus, high internal political efficacy should be associated with a high internal locus of control. This expectation was corroborated by our data (see also Beierlein, Kemper, et al., 2014b; Sigel, 1975). Other associations differed across the two nations: Whereas internal political efficacy was positively related to external locus of control and external political efficacy was positively related to both internal and external locus of control in the UK, we did not find any associations between political efficacy and locus of control in Germany.

One might also suspect that optimism as a personality trait pervades people's sense of (political) efficacy (e.g., Campbell et al., 1954, 1960; Shrivastava, 1989). In line with this reasoning, we found that, in both the UK and Germany, respondents with high internal political efficacy were more optimistic than those with low internal political efficacy. External political efficacy had no significant association with optimism. 
Table 4 Correlations of internal and external political efficacy with relevant variables in the UK and German samples

\begin{tabular}{|c|c|c|c|c|c|c|c|c|}
\hline & \multicolumn{4}{|l|}{ UK } & \multicolumn{4}{|l|}{$\mathrm{DE}$} \\
\hline & \multicolumn{2}{|c|}{ Internal political efficacy } & \multicolumn{2}{|c|}{ External political efficacy } & \multicolumn{2}{|c|}{ Internal political efficacy } & \multicolumn{2}{|c|}{ External political efficac) } \\
\hline & $r$ & $\mathrm{Cl}_{95 \%}$ & $r$ & $\mathrm{Cl}_{95 \%}$ & $r$ & $\mathrm{Cl}_{95 \%}$ & $r$ & $\mathrm{Cl}_{95 \%}$ \\
\hline \multicolumn{9}{|l|}{ Big Five } \\
\hline Extraversion & $.28^{* * *}$ & {$[.19, .36]$} & $.16^{* * *}$ & {$[.07, .25]$} & $.30^{* * *}$ & {$[.21, .38]$} & $.12^{* *}$ & {$[.03, .21]$} \\
\hline Agreeableness & -.01 & {$[-.10, .08]$} & .03 & {$[-.06, .12]$} & .06 & {$[-.03, .15]$} & .06 & {$[-.03, .15]$} \\
\hline Conscientiousness & -.07 & {$[-.16, .02]$} & $-.21^{* * *}$ & {$[-.30,-.12]$} & $.15^{* *}$ & {$[.06, .23]$} & -.07 & {$[-.16, .02]$} \\
\hline Emotional Stability & $.20^{* * *}$ & {$[.11, .29]$} & $.12^{*}$ & {$[.03, .20]$} & $.26^{* * *}$ & {$[.18, .34]$} & .07 & {$[-.02, .16]$} \\
\hline Openness & $.43^{* * *}$ & {$[.36, .50]$} & $.14^{* *}$ & {$[.05, .23]$} & $.33^{* * *}$ & {$[.25, .41]$} & $.12^{*}$ & {$[.03, .20]$} \\
\hline General self-efficacy & $.32^{* * *}$ & {$[.24, .40]$} & .09 & {$[-.00, .18]$} & $.41^{* * *}$ & {$[.33, .48]$} & $.09^{*}$ & {$[.00, .18]$} \\
\hline \multicolumn{9}{|l|}{ Locus of control } \\
\hline Internal & $.25^{* * *}$ & {$[.16, .33]$} & $.22^{* * *}$ & {$[.14, .31]$} & $.17^{* * *}$ & {$[.08, .25]$} & .01 & {$[-.08, .10]$} \\
\hline External & $.16^{* * *}$ & {$[.07, .25]$} & $.33^{* * *}$ & {$[.25, .41]$} & -.07 & {$[-.16, .02]$} & $.09^{*}$ & {$[.00, .18]$} \\
\hline Optimism-pessimism & $.20^{* * *}$ & {$[.11, .28]$} & $.13^{* *}$ & {$[.04, .22]$} & $.22^{* * *}$ & {$[.13, .30]$} & $.13^{* *}$ & {$[.04, .21]$} \\
\hline Interpersonal trust & $.17^{* * *}$ & {$[.08, .25]$} & $.16^{* * *}$ & {$[.08, .25]$} & $.10^{*}$ & {$[.01, .19]$} & $.28^{* * *}$ & {$[.20, .37]$} \\
\hline Life satisfaction & $.21^{* * *}$ & {$[.12, .30]$} & $24^{* * *}$ & {$[.16, .33]$} & $20^{* * *}$ & {$[.11, .28]$} & $.17^{* * *}$ & {$[.08, .25]$} \\
\hline Left-right self- placement & .01 & {$[-.10, .12]$} & $.28^{* * *}$ & {$[.18, .38]$} & $-.14^{* *}$ & {$[-.23,-.04]$} & $-.16^{* *}$ & {$[-.25,-.06]$} \\
\hline \multicolumn{9}{|l|}{ Authoritarianism } \\
\hline Aggression & .05 & {$[-.04, .14]$} & $24^{* * *}$ & {$[.15, .32]$} & -.06 & {$[-.15, .03]$} & -.05 & {$[-.14, .04]$} \\
\hline Submissiveness & .07 & {$[-.02, .16]$} & $.45^{* * *}$ & {$[.37, .52]$} & $-.11^{*}$ & {$[-.19,-.02]$} & $.32^{* * *}$ & {$[.23, .40]$} \\
\hline Conventionalism & -.07 & {$[-.16, .02]$} & $.32^{* * *}$ & {$[.24, .40]$} & -.08 & {$[-.17, .01]$} & .04 & {$[-.05, .13]$} \\
\hline \multicolumn{9}{|l|}{ Justice sensitivity } \\
\hline Victim & .05 & {$[-.04, .14]$} & .05 & {$[-.04, .14]$} & $-.09^{*}$ & {$[-.18,-.00]$} & $-.11^{*}$ & {$[-.20,-.02]$} \\
\hline Observer & $.20^{* * *}$ & {$[.11, .28]$} & .02 & {$[-.07, .11]$} & $.15^{* *}$ & {$[.06, .24]$} & .03 & {$[-.06, .12]$} \\
\hline Offender & $.19^{* * *}$ & {$[.10, .27]$} & $.16^{* * *}$ & {$[.07, .24]$} & .06 & {$[-.03, .15]$} & .03 & {$[-.06, .12]$} \\
\hline Beneficiary & $24^{* * *}$ & {$[.15, .32]$} & $.28^{* * *}$ & {$[.19, .36]$} & -.01 & {$[-.10, .08]$} & $.13^{* *}$ & {$[.04, .22]$} \\
\hline \multicolumn{9}{|l|}{ Social desirability } \\
\hline $\mathrm{PQ}+$ & $.23^{* * *}$ & {$[.15, .32]$} & $.17^{* * *}$ & {$[.08, .26]$} & $.21^{* * *}$ & {$[.13, .30]$} & -.02 & {$[-.11, .07]$} \\
\hline NQ- & $.19^{* * *}$ & {$[.10, .27]$} & $.38^{* * *}$ & {$[.29, .45]$} & .00 & {$[-.09, .09]$} & $.13^{* *}$ & {$[.04, .21]$} \\
\hline \multicolumn{9}{|l|}{ Sociodemographic variables } \\
\hline Employment & $.16^{* *}$ & {$[.06, .27]$} & $.15^{* *}$ & {$[.04, .25]$} & $.13^{*}$ & {$[.01, .23]$} & $.16^{* *}$ & {$[.05, .27]$} \\
\hline Income & $.23^{* * *}$ & {$[.14, .32]$} & $.19^{* * *}$ & {$[.10, .28]$} & $.27^{* * *}$ & {$[.18, .35]$} & $.12^{*}$ & {$[.02, .21]$} \\
\hline Educational attainment & $.19^{* * *}$ & {$[.10, .27]$} & .09 & {$[-.00, .18]$} & $.26^{* * *}$ & {$[.17, .34]$} & $.12^{* *}$ & {$[.03, .21]$} \\
\hline Age & -.04 & {$[-.14, .05]$} & $-.12^{*}$ & {$[-.21,-.03]$} & $.17^{* * *}$ & {$[.08, .25]$} & $-.19 * * *$ & {$[-.27,-.10]$} \\
\hline Gender & $-.18^{* * *}$ & {$[-.27,-.09]$} & -.04 & {$[-.14, .04]$} & $-.20^{* * *}$ & {$[-.28,-.11]$} & -.03 & {$[-.12, .06]$} \\
\hline
\end{tabular}

UK United Kingdom $\left(N=468 ; N_{\text {Left-right self-placement }}=325 ; N_{\text {Employment }}=339 ; N_{\text {Income }}=431\right), D E$ Germany $\left(N=474 ; N_{\text {Left-right self-placement }}=394 ; N_{\text {Employment }}=309 ;\right.$ $\left.N_{\text {Income }}=449\right), C l$ confidence interval, $P Q+$ exaggerating positive qualities, $N Q$ - minimizing negative qualities. Optimism-pessimism: very pessimistic (1)-very optimistic (7). Employment: $1=$ unemployed, $2=$ employed. Gender: $1=$ male, $2=$ female ${ }^{*} p<.05,{ }^{* *} p<.01,{ }^{* * *} p<.001$

As outlined in the Theoretical background section, external political efficacy should correlate positively with trust (e.g., Balch, 1974; Craig, 1979; Niemi et al., 1991). We corroborated this finding in both nations. In contrast, internal political efficacy was positively related to interpersonal trust in the UK but not in Germany.
A high sense of political efficacy should be associated with high subjective well-being (e.g., Whiteley et al., 2010). In line with this assumption, we found that internal and external political efficacy were positively associated with life satisfaction (e.g., Whiteley et al., 2010).

Consistent with the findings of Beierlein, Kemper, et al. (2014b), internal and external political efficacy were 
independent of left-right self-placement (except for a positive correlation with external political efficacy in the UK).

In agreement with previous studies (e.g., Lane, 1955), internal political efficacy was uncorrelated with authoritarianism in both nations. Although external political efficacy was positively related to authoritarianism in the UK, we found no associations between the two variables in Germany (except for a positive association with the submissiveness subscale).

The correlational pattern of political efficacy with the four justice sensitivity subscales differed considerably across subscales and nations. In the UK, internal political efficacy correlated positively with observer, offender, and beneficiary sensitivity. External political efficacy correlated positively with offender and beneficiary sensitivity. We found no association between political efficacy and justice sensitivity in Germany.

Generally, people tend to bias their answers to selfefficacy questions to appear more favorable to others. In line with this observation, the correlations of political efficacy with social desirability were consistently positive in the UK. In Germany, in contrast, answers to the items of the external political efficacy subscale do not appear to have been biased by social desirability, but positive qualities were exaggerated when responding to the internal political efficacy items.

We also calculated correlations between political efficacy and relevant sociodemographic variables-namely employment, income, educational attainment, age, and gender. It has been consistently found that people with a high socioeconomic status have high levels of internal political efficacy (e.g., Beierlein, Kemper, et al., 2014b; Craig \& Maggiotto, 1982; Morrell, 2003; Niemi et al., 1991). Our data support this finding: High internal political efficacy was associated with high income, high educational attainment, and male gender in both the UK and Germany, and with high age in Germany only. We further found barely no significant associations between external political efficacy and sociodemographic variables (except for a positive correlation with income in the UK and a negative correlation with age in Germany).

In sum, the pattern of correlations with relevant variables (i.e., the nomological network, see Table 4) confirms the validity of PESS/PEKS in both nations.

\section{Measurement invariance across the UK and Germany}

To investigate to what degree the PESS/PEKS subscales were measurement invariant across the UK and Germany, we estimated multigroup confirmatory factor analysis models (Vandenberg \& Lance, 2000; Widaman \& Reise, 1997). We tested four successive levels of measurement invariance: configural invariance (same measurement model), metric invariance (same loadings), scalar invariance (same intercepts), and uniqueness invariance (same residual variances). To decide on the achieved level of measurement invariance, we applied Chen's (2007) cutoff criteria for changes in fit indices. When examining global fit indices, we again applied $\mathrm{Hu}$ and Bentler's (1999) cutoff criteria. We tested measurement invariance based on the essentially tau-equivalent model. For identification purposes, we fixed the first loading and intercept of each factor to one. Due to the identification strategy and our basic model, the configural model equals the metric model. We used MLR estimation to fit the model.

According to these heuristics, the metric model fit quite well $\left(\chi^{2}(6)=30.73, p<.001\right.$, CFI $=.978$, RMSEA $=.094$, SRMR $=.024, \mathrm{BIC}=9729)$, although the RMSEA was clearly too large. Because the other fit indices pointed to a good model fit, and further modifications were not theoretically justified, we accepted the metric model. Thus, latent variances and covariances can be compared across nations (e.g., Bluemke et al., 2016). The scalar model also fit well $\left(\chi^{2}(8)=\right.$ $30.89, p<.001$, CFI $=.980$, RMSEA $=.078$, SRMR $=.024$, BIC = 9716). When comparing the scalar with the metric model $\left(\Delta X^{2}(2)=0.44, p=.804, \Delta \mathrm{CFI}=.002, \triangle\right.$ RMSEA $=$ $-.016, \Delta \mathrm{SRMR}=.000, \Delta \mathrm{BIC}=-13)$, we could accept it according to Chen's (2007) cutoff values. We even found a lower RMSEA for the scalar compared to the metric model. Scalar invariance implies that latent means additional to latent variance and covariances can be compared across the UK and Germany (e.g., Bluemke et al., 2016). We also accepted the uniqueness model because the global model fit quite well $\left(x^{2}(12)=32.28, p<.001\right.$, CFI $=.978$, RMSEA $=$ $.067, \mathrm{SRMR}=.032, \mathrm{BIC}=9702)^{7}$ and the misspecification induced when restricting the residual variances was negligible $\left(\Delta \chi^{2}(4)=8.59, p=.072, \Delta\right.$ CFI $=-.002, \Delta$ RMSEA $=-.011$, $\triangle \mathrm{SRMR}=.008, \triangle \mathrm{BIC}=-14)$. Uniqueness invariance implies that researchers working with PESS/PEKS can compare manifest scale scores (means and variances) and correlations across language groups without systematic bias (e.g., Bluemke et al., 2016).

\section{Discussion and conclusion}

The Political Efficacy Short Scale (PESS) is the Englishlanguage adaptation of the original German-language ultrashort scale measuring internal and external political efficacy (Beierlein, Kemper, et al., 2014b). The results of our validation study show that PESS is a sufficiently reliable and valid measure whose psychometric properties are comparable to those of the German-language source version. Furthermore, we confirmed the postulated two-factor structure of political efficacy (internal and external efficacy; Balch, 1974) for both PESS and PEKS.

\footnotetext{
${ }^{7}$ Metric-robust CFI $=.985$, robust RMSEA $=.092$; scalar-robust CFI $=.986$, robust RMSEA $=.077$; uniqueness-robust $\mathrm{CFI}=.982$, robust RMSEA $=.072$.
} 
However, as already reported by Beierlein, Kemper, et al. (2014b), we found stronger test-retest reliability for internal political efficacy than for external political efficacy after an interval of 3 to 4 weeks. Thus, internal political efficacy seems to be more stable over time than external political efficacy. A possible reason for this is that external political efficacy might be more strongly influenced by political events and changing political landscapes (Beierlein, Kemper, et al., 2014b). However, the internal consistencies were equally high across both factors of political efficacy.

We found associations between (at least one of) the PESS/PEKS subscales and the Big Five personality traits Openness, Extraversion, Emotional Stability, and Conscientiousness. Further associations included general self-efficacy, locus of control, optimism, interpersonal trust, life satisfaction, left-right self-placement, authoritarianism, justice sensitivity, and the sociodemographic variables income, age, educational attainment, and gender.

Both subscales of PESS/PEKS tended to be biased by social desirability, a phenomenon that is not unique to PESS/PEKS but rather typical of self-report data in general (van de Mortel, 2008). When assessing the tendency to respond in a socially desirable way by means of a social desirability scale (e.g., KSE-G; Nießen, Partsch, et al., 2019), results can be controlled for social desirability bias.

Measurement invariance testing across the UK and Germany suggested that the scale shows strict invariance (loadings, intercepts, and uniquenesses), thus implying the comparability of manifest scale scores and correlations across the two nations.

We chose the UK over any other English-speaking nation for practical reasons: The online access panel provider respondi AG was able to recruit participants from both Germany and the UK. Even though we do not expect largely diverging results in other Englishspeaking nations, future research may address this point.

For research purposes, as an ultra-short scale, both components of political efficacy (internal and external) measured by PESS can thus be used in measurement settings with severe time limitations by computing the mean scores of each subscale separately.

\section{Supplementary Information}

The online version contains supplementary material available at https://doi. org/10.1186/s42409-020-00018-z

Additional File 1: Table S1. Quotas: Target and Real Sample Sizes for the UK and Germany.

Additional File 2. Answer Sheet (English Version) PESS.

Additional File 3. Answer Sheet (German Version) PEKS.

Additional File 4. $R$ Code for Analysis.
Additional File 5. $R$ Output for Analysis.

Additional File 6: Table S2. Reference Ranges of the PESS/PEKS Scale Scores for the Total Population and Separately for Gender and Age Groups.

\section{Abbreviations}

ANES: American National Election Studies; ASKU: Allgemeine

Selbstwirksamkeit Kurzskala [General Self-Efficacy Short Scale]; BFI-2-XS: Extrashort form of the Big Five Inventory-2; BIC: Bayesian information criterion; CASI: Computer-assisted self-administered interviewing; CFI: Comparative fit index; DE: Germany; ESS: European Social Survey; GSE-3: General Self-Efficacy Short Scale-3; IE-4: Internal-External Locus of Control Short Scale-4; JSS8: Justice Sensitivity Short Scales-8; KSA-3: Authoritarianism Short Scale; KSEG: Social Desirability-Gamma Short Scale; KUSIV3: Interpersonal Trust Short Scale; L-1: General Life Satisfaction Short Scale; MLR: Robust maximum likelihood; PEKS: Political Efficacy Kurzskala [Short Scale]; PESS: Political Efficacy Short Scale; RMSEA: Root Mean Square Error of Approximation; SOP2: Optimism-Pessimism Short Scale-2; SRMR: Standardized Root Mean Square Residual; TRAPD: Translation, Review, Adjudication, Pretesting, and Documentation; UK: United Kingdom; USS-8: UngerechtigkeitssensibilitätSkalen-8 [Injustice Sensitivity-Scales-8]

\section{Acknowledgements}

We would like to thank Melanie Partsch from GESIS - Leibniz Institute for the Social Sciences for preparing the data.

\section{Authors' contributions}

All authors read and approved the final manuscript.

\section{Funding}

The study was funded by an internal grant provided by GESIS - Leibniz Institute for the Social Sciences, Mannheim, Germany. Open Access funding enabled and organized by Projekt DEAL.

\section{Availability of data and materials}

The dataset supporting the conclusions of this article available in the GESIS SowiDataNet | datorium repository (https://doi.org/10.7802/2081).

\section{Ethics approval and consent to participate}

Participants consented to their participation in the anonymous survey. Approval by an ethics committee was not necessary.

Consent for publication

Not applicable.

\section{Competing interests}

We have no competing interests to disclose.

Received: 29 July 2020 Accepted: 10 November 2020

Published online: 04 January 2021

\section{References}

Aiken, L. R., \& Groth-Marnat, G. (2006). Psychological testing and assessment (12th ed.). Pearson.

Almond, G. A., \& Verba, S. (1963). The civic culture. University Press https://www. jstor.org/stable/j.ctt183pnr2.

Andreß, H.-J., Meulemann, H., Diekmann, A., Feger, H., Huinink, J., Schmitt-Beck, R., \& Solga, H. (2011). Allgemeine Bevölkerungsumfrage der Sozialwissenschaften ALLBUS 2004 [General population survey of the Social Sciences ALLBUS 2004] (ZA3762; version 2.0.0) [Data set]. GESIS Data Archive. https://doi.org/1 $0.4232 / 1.10977$

Balch, G. I. (1974). Multiple indicators in survey research: The concept "sense of political efficacy". Political Methodology, 1(2), 1-43 https:/www.jstor.org/ stable/25791375.

Beierlein, C., Asbrock, F., Kauff, M., \& Schmidt, P. (2014). Die Kurzskala Autoritarismus (KSA-3): Ein ökonomisches Messinstrument zur Erfassung dreier Subdimensionen autoritärer Einstellungen [The Authoritarianism Short Scale A (KSA-3): An economic measurement tool to capture three subdimensions of authoritarian attitudes]. Zusammenstellung sozialwissenschaftlicher Items und Skalen (ZIS). https://doi.org/10.6102/zis228. 
Beierlein, C., Baumert, A., Schmitt, M., Kemper, C. J., Kovaleva, A., \& Rammstedt, B. (2014). Ungerechtigkeitssensibilität-Skalen-8 (USS-8) [Injustice Sensitivity Scale-8 (USS-8)]. Zusammenstellung sozialwissenschaftlicher Items und Skalen (ZIS). https://doi.org/10.6102/zis36.

Beierlein, C., Kemper, C. J., Kovaleva, A., \& Rammstedt, B. (2014b). Political Efficacy Kurzskala (PEKS) [Political Efficacy Short Scale (PESS)]. Zusammenstellung sozialwissenschaftlicher Items und Skalen (ZIS). https://doi.org/10.6102/zis34.

Beierlein, C., Kemper, C. J., Kovaleva, A. J., \& Rammstedt, B. (2014a). Interpersonales Vertrauen (KUSIV3) [Interpersonal Trust (KUSIV3)]. Zusammenstellung sozialwissenschaftlicher Items und Skalen (ZIS). https://doi.org/10.6102/zis37.

Beierlein, C., Kovaleva, A., Kemper, C. J., \& Rammstedt, B. (2014). Allgemeine Selbstwirksamkeit Kurzskala (ASKU) [General Self-Efficacy Short Scale (ASKU)]. Zusammenstellung sozialwissenschaftlicher Items und Skalen (ZIS). https://doi.org/10.6102/zis35.

Beierlein, C., Kovaleva, A., László, Z., Kemper, C. J., \& Rammstedt, B. (2015). Kurzskala zur Erfassung der Allgemeinen Lebenszufriedenheit (L-1) [General Life Satisfaction Short Scale (L-1)]. Zusammenstellung sozialwissenschaftlicher Items und Skalen (ZIS). https://doi.org/10.6102/zis229.

Bluemke, M., Jong, J., Grevenstein, D., Mikloušić, I., \& Halberstadt, J. (2016). Measuring cross-cultural supernatural beliefs with self- and peer-reports. PLoS One, 11, Article e0164291. https://doi.org/10.1371/journal.pone.0164291.

Breyer, B. (2015). Left-Right Self-Placement (ALLBUS). Zusammenstellung sozialwissenschaftlicher Items und Skalen. https://doi.org/10.6102/zis83.

Brosseau-Liard, P. E., \& Savalei, V. (2014). Adjusting incremental fit indices for nonnormality. Multivariate Behavioral Research, 49(5), 460-570. https://doi.org/10.1080/00273171.2014.933697.

Brosseau-Liard, P. E., Savalei, V., \& Li, L. (2012). An investigation of the sample performance of two nonnormality corrections for RMSEA. Multivariate Behavioral Research, 47(6), 904-930. https://doi.org/10.1080/00273171.2012. 715252.

Campbell, A., Gurin, G., \& Miller, W. E. (1954). The voter decides. Row, Peterson, and Co.

Campbell, A., Converse, P. E., Miller, W. E., \& Stokes, D. E. (1960). The American voter. John Wiley \& Sons.

Chen, F. F. (2007). Sensitivity of goodness of fit indexes to lack of measurement invariance. Structural Equation Modeling, 14(3), 464-504. https://doi.org/10. 1080/10705510701301834

Cohen, J. (1992). A power primer. Psychological Bulletin, 112(1), 155-159. https://doi.org/10.1037/0033-2909.112.1.155.

Coleman, K. M., \& Davis, C. L. (1976). The structural context of politics and dimensions of regime performance: Their importance for the comparative study of political efficacy. Comparative Political Studies, 9(2), 189-206. https://doi.org/10.1177/001041407600900203.

Condon, M., \& Holleque, M. (2013). Entering politics: General self-efficacy and voting behavior among young people. Political Psychology, 34(2), 167-181. https://doi.org/10.1111/pops.12019.

Cooper, C. A., Golden, L., \& Socha, A. (2013). The Big Five personality factors and mass politics. Journal of Applied Social Psychology, 43(1), 68-82. https://doi.org/10.1111/j.1559-1816.2012.00982.x.

Craig, S. C. (1979). Efficacy, trust, and political behavior: An attempt to resolve a lingering conceptual dilemma. American Politics Quarterly, 7(1), 225-239. https://doi.org/10.1177/1532673X7900700207.

Craig, S. C., \& Maggiotto, M. A. (1982). Measuring political efficacy. Political Methodology, 8(3), 85-109 https://www.jstor.org/stable/25791157.

Easton, D., \& Dennis, J. (1967). The child's acquisition of regime norms: Political efficacy. American Political Science Review, 61(1), 25-38. https://doi.org/10. 2307/1953873

European Social Survey (n.d.). ESS round 8: question design template - new core items. Retrieved October 08, 2020, from https://www.europeansocialsurvey. org/docs/methodology/core_ess_questionnaire/ESS8_political_efficacy_final_ template.pdf

Falter, J. W., Gabriel, O. W., \& Rattinger, H. (2015). Politische Einstellungen, politische Partizipation und Wählerverhalten im vereinigten Deutschland 2002 (Studie zur Bundestagswah/ 2002) [Political attitudes, political participation, and voter behavior in united Germany 2002 (study on the 2002 federal elections)] (ZA3861; Version 3.0.0) [Data set]. GESIS Data Archive. doi: https://doi.org/10. 4232/1.11967.

Harkness, J. A. (2003). Questionnaire translation. In J. A. Harkness, F. van de Vijver, \& P. P. Mohler (Eds.), Cross-cultural survey methods, (pp. 35-56). Wiley.
Hu, L., \& Bentler, P. M. (1999). Cutoff criteria for fit indexes in covariance structure analysis: Conventional criteria versus new alternatives. Structural Equation Modeling, 6(1), 1-55. https://doi.org/10.1080/10705519909540118.

International Test Commission (2010). International Test Commission guidelines for translating and adapting tests. http://www.intestcom.org.

Jorgensen, T. D., Pornprasertmanit, S., Schoemann, A. M., \& Rosseel, Y. (2019). semTools: Useful tools for structural equation modeling. https://CRAN.R-project. org/package=semTools.

Kemper, C. J., Beierlein, C., Bensch, D., Kovaleva, A., \& Rammstedt, B. (2014). Soziale Erwünschtheit-Gamma (KSE-G) [Social Desirability-Gamma Short Scale (KSE-G)]. Zusammenstellung sozialwissenschaftlicher Items und Skalen (ZIS). https://doi.org/10.6102/zis186.

Kemper, C. J., Beierlein, C., Kovaleva, A., \& Rammstedt, B. (2014). Skala Optimismus-Pessimismus-2 (SOP2) [Optimism-Pessimism Short Scale-2 (SOP2)]. Zusammenstellung sozialwissenschaftlicher Items und Skalen (ZIS). https://doi.org/10.6102/zis185.

Kemper, C. J., \& Menold, N. (2014). Nuisance or remedy? The utility of stylistic responding as an indicator of data fabrication in surveys. Methodology, 10(3), 92-99. https://doi.org/10.1027/1614-2241/a000078.

Kemper, C. J., Trapp, S., Kathmann, N., Samuel, D. B., \& Ziegler, M. (2019). Short versus long scales in clinical assessment: Exploring the trade-off between resources saved and psychometric quality lost using two measures of obsessive-compulsive symptoms. Assessment, 26(5), 767-782. https://doi.org/10.1177/1073191118810057.

Kovaleva, A., Beierlein, C., Kemper, C. J., \& Rammstedt, B. (2014). InternaleExternale-Kontrollüberzeugung-4 (IE-4) [Internal-External Locus of Control-4 (IE-4)]. Zusammenstellung sozialwissenschaftlicher Items und Skalen (ZIS). https://doi.org/10.6102/zis184.

Lane, R. E. (1955). Political personality and electoral choice. American Political Science Review, 49(1), 173-190. https://www.jstor.org/stable/1951646.

McDonald, R. P. (1999). Test theory: A unified treatment. Lawrence Erlbaum Associates. https://doi.org/10.1111/j.2044-8317.1981.tb00621.x.

Meade, A. W., \& Craig, S. B. (2012). Identifying careless responses in survey data. Psychological Methods, 17(3), 437-455. https://doi.org/10.1037/a0028085.

Miller, A. H. (1974). Political issues and trust in government: 1964-1970. American Political Science Review, 68(3), 951-972. https://doi.org/10.2307/1959140.

Miller, W. E., \& Traugott, S. A. (1989). American National Election Studies data sourcebook, 1952-1986. Harvard University Press.

Minton, H. L. (1972). Power and personality. In J. T. Tedeschi (Ed.), The social influence processes, (pp. 100-149). Aldine.

Morrell, M. E. (2003). Survey and experimental evidence for a reliable and valid measure of internal political efficacy. The Public Opinion Quarterly, 67(4), 589602. https://www.jstor.org/stable/3521695.

Muller, E. N. (1970). Cross-national dimensions of political competence. American Political Science Review, 64(3), 792-809. https://doi.org/10.2307/1953463.

Niemi, R. G., Craig, S. C., \& Mattei, F. (1991). Measuring internal political efficacy in the 1988 National Election Study. The American Political Science Review, 85(4), 1407-1413. https://doi.org/10.2307/1963953.

Nießen, D., Beierlein, C., Rammstedt, B., \& Lechner, C. M. (2020). An Englishlanguage adaptation of the Interpersonal Trust Short Scale (KUSIV3). Measurement Instruments for the Social Sciences, 2, Article 10. https://doi.org/10.1186/s42409-020-00016-1.

Nießen, D., Groskurth, K., Rammstedt, B., \& Lechner, C. M. (2020). An Englishlanguage adaptation of the General Life Satisfaction Short Scale (L-1). Zusammenstellung sozialwissenschaftlicher Items und Skalen (ZIS). https://doi.org/10.6102/zis284.

Nießen, D., Partsch, M., Kemper, C. B., \& Rammstedt, B. (2019). An Englishlanguage adaptation of the Social Desirability-Gamma Short Scale (KSE-G). Measurement Instruments for the Social Sciences, 1, Article 2. https://doi.org/10. 1186/s42409-018-0005-1.

Nießen, D., Schmidt, I., Beierlein, C., \& Lechner, C. M. (2019). An English-language adaptation of the Authoritarianism Short Scale (KSA-3). Zusammenstellung sozialwissenschaftlicher Items und Skalen (ZIS). https://doi.org/10.6102/zis272.

Rammstedt, B., Danner, D., Soto, C. J., \& John, O. P. (2020). Validation of the short and extra-short forms of the Big Five Inventory-2 (BFI-2) and their German adaptations. European Journal of Psychological Assessment, 36(1), 149-161. https://doi.org/10.1027/1015-5759/a000481

Raykov, T. (1997). Estimation of composite reliability for congeneric measures. Applied Psychological Measurement, 21(2), 173-184. https://doi.org/10.1177/ 01466216970212006 
Renshon, S. A. (1975). Psychological needs, personal control, and political participation. Canadian Journal of Political Science/Revue canadienne de science politique, 8(1), 107-116 https://www.jstor.org/stable/3230985.

Revelle, W. (2018). psych: Procedures for personality and psychological research. https://CRAN.R-project.org/package=psych.

Rosseel, Y. (2012). lavaan: An R package for structural equation modeling. Journal of Statistical Software, 48(2), 1-36. http://www.jstatsoft.org/v48/i02/.

Šerek, J., Machackova, H., \& Macek, P. (2017). The chicken or egg question of adolescents' political involvement: Longitudinal analysis of the relation between young people's political participation, political efficacy, and interest in politics. Zeitschrift für Psychologie, 225(4), 347-356. https://doi.org/10.1027/ 2151-2604/a000297.

Shrivastava, R. (1989). Political efficacy: A comparative study of the United States, the United Kingdom, and India. Youth \& Society, 21(2), 170-195. https://doi. org/10.1177/0044118X89021002003.

Sigel, R. S. (1975). Psychological antecedents and political involvement: The utility of the concept of locus-of-control. Social Science Quarterly, 56(2), 315-323. https://www.jstor.org/stable/42859527.

Soto, C. J., \& John, O. P. (2017). Short and extra-short forms of the Big Five Inventory-2: The BFI-2-S and BFI-2-XS. Journal of Research in Personality, 68, 69-81. https://doi.org/10.1016/j.jp.2017.02.004.

van de Mortel, T. F. (2008). Faking it: Social desirability response bias in self-report research. Australian Journal of Advanced Nursing, 25(4), 40-48. https://www. ajan.com.au/archive/Nol25/Nol_25-4_vandeMortel.pdf.

Vandenberg, R. J., \& Lance, C. E. (2000). A review and synthesis of the measurement invariance literature: Suggestions, practices, and recommendations for organizational research. Organizational Research Methods, 3(1), 4-70. https://doi.org/10.1177/109442810031002

Vecchione, M., \& Caprara, G. V. (2009). Personality determinants of political participation: The contribution of traits and self-efficacy beliefs. Personality and Individual Differences, 46(4), 487-492. https://doi.org/10.1016/j.paid.2008. 11.021

Vecchione, M., Caprara, G. V., Caprara, M. G., Alessandri, G., Tabernero, C., \& González-Castro, J. L. (2014). The Perceived Political Self-Efficacy Scale-Short Form (PPSE-S): a validation study in three Mediterranean countries. CrossCultural Research, 48(4), 368-384. https://doi.org/10.1177/1069397114523924

Vetter, A. (1997). Political efficacy: alte und neue Meßmodelle im Vergleich [Political efficacy: old and new measurement models compared]. Kölner Zeitschrift für Soziologie und Sozialpsychologie, 49(1), 53-73.

Whiteley, P., Clarke, H. D., Sanders, D., \& Stewart, M. C. (2010). Government performance and life satisfaction in contemporary Britain. The Journal of Politics, 72(3), 733-746. https://doi.org/10.1017/S0022381610000137.

Widaman, K. F., \& Reise, S. P. (1997). Exploring the measurement invariance of psychological instruments: Applications to the substance use domain. In K. J. Bryant, M. Windle, \& S. G. West (Eds.), The science of prevention: Methodological advances from alcohol and substance abuse research, (pp. 281-324). American Psychological Association.

\section{Publisher's Note}

Springer Nature remains neutral with regard to jurisdictional claims in published maps and institutional affiliations.

Ready to submit your research? Choose BMC and benefit from:

- fast, convenient online submission

- thorough peer review by experienced researchers in your field

- rapid publication on acceptance

- support for research data, including large and complex data types

- gold Open Access which fosters wider collaboration and increased citations

- maximum visibility for your research: over $100 \mathrm{M}$ website views per year

At BMC, research is always in progress.

Learn more biomedcentral.com/submissions 